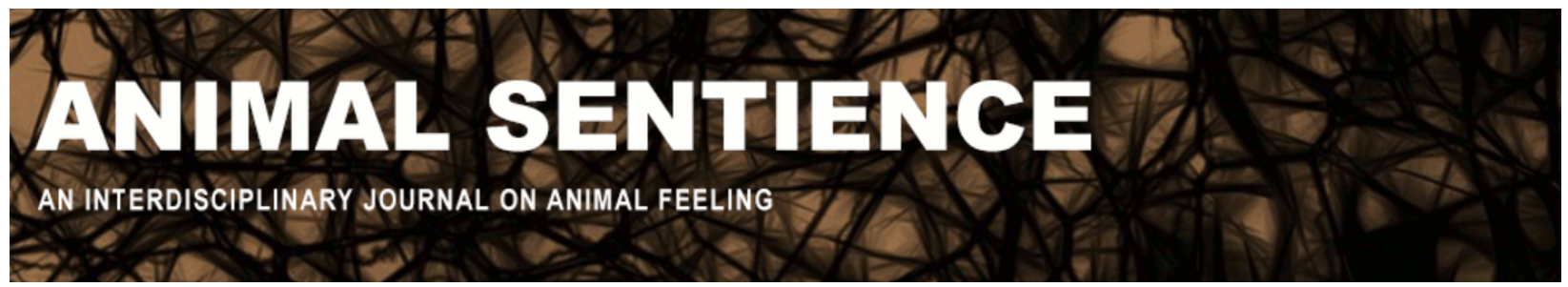

Woodruff, Michael L. (2019) Smart sheep need more protection. Animal Sentience 25(9)

DOI: $10.51291 / 2377-7478.1442$

Date of submission: 2019-05-13

Date of acceptance: 2019-05-20

(c)

This article has appeared in the journal Animal

Sentience, a peer-reviewed journal on animal

cognition and feeling. It has been made open access,

free for all, by WellBeing International and deposited

in the WBI Studies Repository. For more information,

please contact

wbisr-info@wellbeingintl.org.

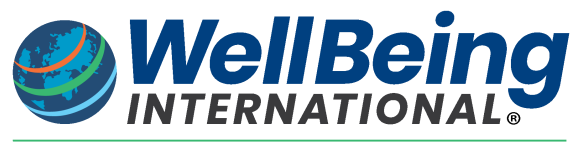

SOLUTIONS FOR PEOPLE, ANIMALS AND ENVIRONMENT 


\title{
Smart sheep need more protection
}

Commentary on Marino \& Merskin on Sheep Complexity

\author{
Michael L. Woodruff \\ Biomedical Sciences \\ East Tennessee State University
}

\begin{abstract}
The target article unequivocally establishes that sheep are far more intelligent and cognitively sophisticated than is generally acknowledged. For this reason, the authors advocate for significantly more stringent regulation of agricultural and research practices when sheep are used. I briefly review the existing US regulations governing the use of sheep in research and discuss the extent to which they are applied to sheep. I then discuss weaknesses in the current regulations, concluding that they should be changed to mandate housing all research animals in environments that accommodate the psychosocial needs of each species.
\end{abstract}

Michael L. Woodruff is Professor Emeritus of Biomedical Sciences in the Quillen College of Medicine at East Tennessee State University. His current research interests include cognitive neuroscience and the philosophy of mind. Website

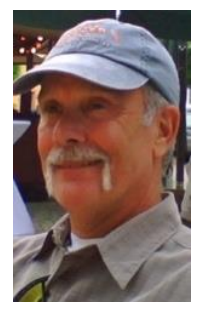

1. Introduction. Lori Marino and her colleagues have undertaken the task of reviewing the scientific literature concerning the cognitive abilities of herd animals such as cows (Marino \& Allen, 2017) and sheep (Marino \& Merskin, 2019) (M\&M). They convincingly demonstrate that these species are much more intelligent and cognitively sophisticated than is generally acknowledged. For this reason, the main goal of the target article is to foster reconsideration of "the use of sheep as commodities in modern agricultural production and in invasive research." This is an important goal, as the welfare of sheep used both on the farm and in research is an international concern. As an American biomedical scientist, however, I will limit my commentary to a brief overview of regulations governing the use of sheep in research in the United States, with suggestions for improvements.

2. Disclosure. Before I continue, I disclose my position that animal models have a valid place in biomedical research (Nonneman \& Woodruff, 1994; Woodruff \& Baisden, 1994). I also note that, ironically, those who criticize laboratory animal research occasionally use evidence from such research to support their arguments. For example, M\&M cite the correlation between the activity of neurons in the temporal lobe of sheep and apparent recognition of other sheep and humans. Another example is the use by Jana Brock on her website Love Your Rabbit of one of my publications to verify that rabbits do not enjoy being "tranced" (Ewell et al. 1981). 
3. Welfare of sheep in the laboratory. Title 7 U.S.C. $\S \S 2131-2159$, popularly called the Animal Welfare Act (AWA), is the principal law governing the care and use of research animals in the US. Animal law attorney Pamela Frasch (2016) has identified multiple weaknesses in the AWA, each of which is important, but I will discuss only the one that I think has the greatest impact on the concerns raised by $M \& M$ : the exclusion of several species from protection.

As M\&M note, "farmed animals are not protected by the Animal Welfare Act." They are not protected because the AWA definition of "animals" specifically excludes them, as well as birds, rats and mice. The AWA definition of "animals" is fatuous, and the exclusions are morally indefensible. All animals, at least all vertebrate species, must be included in the AWA. However, I want to make two points regarding research on sheep in US labs.

First, once a sheep enters a laboratory registered with the federal government, it is included in USDA inspections and is counted in the USDA's annual reports. A review of these reports indicates that the number of sheep used in research over the decade from 2008 through 2017 averaged 12,637 per year. This is a much smaller number than the 24,000 cited in the target article. That figure came from the 2000 USDA report (Sheep 101). Hence, the number of sheep used in research has decreased substantially since 2000; in 2017 it comprised 1.5\% of the total number of animals included in the annual USDA reports. Given that rats and mice, the most frequently used research animals, are not included in these reports, the percentage of sheep used in research in the US is probably considerably less than $1 \%$ of the total number of animals. In my view this does not constitute what M\&M describe as a "ubiquitous use in biomedical research." Rather, sheep appear to be used selectively in models of specific diseases.

Second, M\&M state that the procedures done on sheep in laboratories "are not limited or regulated in any significant way." This statement presents too dire a picture. The Public Health Service (PHS) Policy on Humane Care and Use of Laboratory Animals provides additional guidelines for the treatment of research animals. These guidelines apply to all vertebrates. The Office of Laboratory Animal Welfare (OLAW) monitors compliance with these guidelines by any institution receiving funding from any PHS component (e.g., $\mathrm{NIH}, \mathrm{CDC}$ ). This monitoring includes sheep. Because the penalty for not following PHS guidelines is loss of federal research funding, in practice much of the biomedical research on sheep in the US is regulated for conformity with PHS guidelines.

4. Required standards for protection of animals are still inadequate. That written, I cannot disagree with the concerns expressed in the target article and will point out some significant problems with the current regulatory environment. The PHS policy applies only to sheep used in federally funded research. Therefore, sheep used in privately funded or institutionally funded research have no legal protection. In addition, as Frasch (2016) emphasizes, PHS policy provides only guidelines, not regulatory mandates. Thus, compliance is voluntary, which allows considerable latitude in the interpretation of the guidelines. Furthermore, USDA inspectors are concerned only with violations of AWA regulations, and OLAW does not do routine inspections but relies upon complaints before investigating potential instances of noncompliance with protocols described in funded grants. Therefore, at a minimum, the guidelines associated with the PHS policy, expanded to include all sentient species (Woodruff, 2019), should be incorporated into AWA as law. Furthermore, because OLAW staff has special expertise in laboratory animals, OLAW should be mandated to do routine inspections of all animal research facilities. 
These recommended changes in the existing AWA, however, are the minimum. If we are to continue to use animals in research and agriculture, we must recognize that their welfare requires more than the avoidance of pain and the provision of maintenance and housing that keeps them apparently physically healthy. The important work done by Marino and her colleagues (Marino \& Allen, 2017; Marino \& Merskin, 2019) tells us that animal welfare requires close and continued attention to the unique cognitive abilities and complexity of all species. The environments in which research animals are housed must be designed to accommodate the unique psychosocial needs of a species.

\section{References}

Ewell, A. H., Jr., Cullen, J. M., \& Woodruff, M. L. (1981). Tonic immobility as a predator defense in the rabbit (Oryctolagus cuniculus). Behavioral \& Neural Biology, 31: 483-489.

Frasch, P. D. (2016). Gaps in US animal welfare law for laboratory animals: Perspectives from an animal law attorney. ILAR Journal, 57: 285-292.

Marino, L., \& Allen, K. (2017). The psychology of cows. Animal Behavior and Cognition, 4: 474498.

Marino, L., \& Merskin, D. (2019). Intelligence, complexity, and individuality in sheep. Animal Sentience 25(1).

Nonneman, A. J., \& Woodruff, M. L. (1994). Types of animal models and the implications of their use. In M. L. Woodruff \& A. J. Nonneman (Eds.), Toxin-Induced Models of Neurological Disorders (pp. 1-15). New York, NY: Plenum Publishing.

Woodruff, M. L. (2019). Sentience is the foundation of animal rights. Animal Sentience 23(18).

Woodruff, M. L. \& Baisden, R. H. (1994). Trimethyltin neuropathology: A model of the forebrain pathology present in Alzheimer's disease? In M. L. Woodruff \& A. J. Nonneman (Eds.), ToxinInduced Models of Neurological Disorders (pp. 319-335). New York, NY: Plenum Publishing. 